\title{
Medical, Scientific And Commercial Uses Of Roentgen's X-Rays Today
}

Charles J. Capps III, (E-mail: mgt_cjc@shsu.edu), Sam Houston State University

\begin{abstract}
This article is an overview of a few current medical, scientific and commercial uses of an early information system, Roentgen's x-rays. At the end a conclusion is drawn and recommendations made.
\end{abstract}

n 1869, Wilhelm Conrad Roentgen received his doctorate of philosophy in physics from the University of Zurich at the age of 24. On November 8, 1895, while experimenting in his University of Wurzburg laboratory in Germany, he discovered unknown radiation that others originally called "roentgen rays." Wilhelm preferred not to glorify himself and instead used the term " $\mathrm{x}$-rays" where "X" stands for the mathematical term for the unknown. X-rays have a wavelength of $1 \times 10^{-8}$ meters. (White, 2005) Merriam-Webster's 2005 Online Dictionary defines $\mathrm{X}$-ray as a transitive verb that means to "examine, treat, or photograph with $\mathrm{X}$ rays." (MerriamWebster, 2005) Beginning with an early experiment that photographically captured the illuminated bones in his wife's hand accentuating her ring, Professor Doctor Roentgen established the scientific foundation for the future medical field of radiology, and he went on to become the first Nobel Laureate in Physics in 1901 for his pioneering discovery of x-rays. Roentgen was both an humble and noble man who thought that because he was a professor at a state university he should not profit from his discovery but that knowledge should be for all. (White, 2005)

Roentgen's revolutionary discovery of the x-ray enabled medical science to utilize diagnostic imaging and treatment, thereby creating an information system useful to medicine. (Friedman and Friedland, 1998) In the beginning, many thought $\mathrm{x}$-rays harmless. Soon, some medical practitioners and scientists believed $\mathrm{x}$-ray radiation carried risk and was hazardous. (Fenster, 2003) After Roentgen's discovery, Thomas Alva Edison intensely researched radiology discovering the fluoroscope. Yet, Edison abandoned the new field of radiology quickly, however, when he recognized the risks involved. His assistant, Clarence Dally, began having health problems shortly after first experimenting with x-rays. Eventually Dally lost both arms to malignant ulceration. He died a painful and horrible death in 1904 and is remembered as the first martyr to radiation. Edison was haunted by Dally's death and adamantly refused to be x-rayed throughout the rest of his 84-year life. (John L. Montgomery, MD and Gary Legwold, 1997)

In 1936, Percy Brown, MD in his book, American Martyrs to Science through the Roentgen Rays, titled the chapters after the names of deceased colleagues and stated, that "Another reason why many pioneer roentgenologists were unduly exposed, with more than one fatal result, was the baseless theory that any untoward skin reactions (radiationdermatitis) in the operator were impossible, or nearly so..." (Brown, 1936) Although exposure to x-rays can lead to disease and cancer, hazards today associated with the use of x-ray technology are minimized.

In Canada, the Consumer and Clinical Radiation Protection Bureau regulates medical x-rays and mammography procedures. Their literature states:

The Medical X-Ray and Mammography Division is responsible for reducing the radiation risks from radiological Xray equipment to patients, users, service personnel, and the general public. We draft regulatory standards and guidelines on the use of equipment, verify compliance with prescribed standards, and provide client consultation on regulatory matters pertaining to radiological X-ray equipment. We carry out research on the safety and risks of radiological procedures and equipment. In addition, we work to improve the quality of mammography in Canada by providing early and more reliable breast cancer detection/diagnosis and ensuring consistent quality of 
mammography services. (Health Canada: The Consumer and Clinical Radiation Protection Bureau website, June 2005)

As a precaution though, operators are monitored to measure amount of radiation absorbed, stand behind panels with small viewing windows to operate $\mathrm{x}$-ray machines, and wear special apparatus to protect themselves.

The health care community uses the x-ray, or information systems the discovery of the x-ray made possible, regularly in medicine, radiology, dentistry, and veterinary science through the use of $x$-rays, fluoroscopes, computer axial tomography (CAT) scans, magnetic resonance imaging (MRI) technology, and position emission tomography (PET) scans that diagnosis bones, tissues, dental problems, respiratory ailments, cancer, heart disease, neurological disorders, Alzheimer's, etc. (Edeiken, 1981, White, 2005 and womenshealthchannel.com, 2005) Also, society's health is improved due to the use of x-rays in food inspection. (White, 2005) Clearly, the discovery of x-rays changed many aspects of our lives while furthering our health.

Our society's culture even includes reference to a supernatural "x-ray vision," which we usually reserve for our national superhero, Superman. Today, medical, dental and veterinary science use the x-ray and/or the concept of diagnostic imaging and treatment to improve the lives of everyday work-a-day Supermen, Superwomen and their Superpets in the following ways:

1. The X-ray and/or X-ray therapy is used to "diagnosis and [for] medical treatment (as of cancer) by controlled application of $\mathrm{X}$ rays.” (Merriam-Webster, 2005)

2. Fluoroscopes use X-rays and allow one to see lungs, or perhaps the bones in the hand or foot real-time. In the 1950 s, some shoe stores had fluoroscopes for young customers and their family to evaluate the foot and fit of the shoe. (Buster Brown Shoe Store Experience, circa mid 1950s)

3. Computer Tomography (CT) scans also known as a Computer Axial Tomography (CAT) scan "is used to create cross-sectional images of structures in the body. In this procedure, x-rays are taken from many different angles and processed through a computer to produce a three-dimensional (3-D) image called a tomogram." (womenshealthchannel.com)

4. Magnetic Resonance Imaging (MRI), "also called magnetic resonance tomography (MRT), is a method of creating images of the inside of opaque organs in living organisms as well as detecting the amount of bound water in geological structures." The technology's original name was nuclear magnetic resonance imaging (NMRI), but the word nuclear was dropped due to its stigma in some people's mind. "It is primarily used to demonstrate pathological or other physiological alterations of living tissues and is a commonly used form of medical imaging." (Wikipedia, 2005)

5. Position Emission Tomography (PET) scan is "a nuclear medicine medical imaging technique which produces a three dimensional image or map of functional processes in the body." (Wikipedia, 2005)

6. The field of radiology continues to advance medical science almost daily. The ability to diagnosis disease at an earlier stage improves treatment and prognosis, and inspires constant research in radiology.

7. Veterinary science uses $\mathrm{x}$-rays and medical imaging to improve animal care by providing almost all the techniques currently available to humans. In addition to traditional dental x-ray practices, many dental offices now include handheld digital devices that expedite oral x-rays.

8. Food inspection information from $\mathrm{x}$-rays helps regulate quality to promote public health.

By and large, Roentgen's discovery of x-rays improved information and medical science, our health care services and the public's health. What's more, information from x-rays continues to advance other sciences as well.

Some scientists use $\mathrm{x}$-ray diffraction to produce a "scattering of $\mathrm{X}$ rays by the atoms of a crystal that produces an interference effect so that the diffraction pattern gives information on the structure of the crystal or the identity of a crystalline substance." (Merriam-Webster, 2005) Others, astronomers, enhance their scientific understanding of the universe by examining $\mathrm{x}$-rays from the stars and emitting $\mathrm{x}$-rays into space. For example, $\mathrm{x}$-ray pictures of the supernova remnant Cassiopeia A produced by composite images taken by three of NASA's observatories included Harvard's Chandra X-ray Observatory. (Harvard University's Chandra X-ray Observatory website, 13 June 2005) As implied above, geologists use Magnetic Resonance Imaging (MRI), also known as 
magnetic resonance tomography (MRT), to detect the amount of bound water in geological structures. (Wikipedia, 2005) And today, young scientists can order a build-it-yourself (adult supervision required) x-ray machine project from All Science Fair Projects online. The project's description states that from an "old radio tube, some copper wire, and other inexpensive materials - total cost: roughly $\$ 20$ - you can construct an X-ray machine that will make good pictures through an inch of wood. [There Are] SAFETY MEASURES THAT YOU MUST OBSERVE. [And You Get] Notes on Roentgen's invention. [And] Highlights of X-ray theory." The advertisement makes it sound like a "really neat" science project! (All Science Fair Projects website, June 2005) Often, medical and scientific use precede commercial and industrial use.

$\mathrm{X}$-rays and diagnostic imaging information systems are used commercially for many examination and control purposes. The security industry use x-rays and diagnostic imaging increasingly at airport checkpoints to decrease the risk of terrorist acts. Passengers and their baggage are routinely examined by x-ray imaging device. In addition, our borders are more secure because of technology that allows law enforcement "night vision" to view movement and activity day and night. In the private sector, Envision Product Design's tag line at their cmosXray.com website states "This is X-ray in the twenty-first century." The Anchorage, Alaska, company offers high resolution, large format three dimensional X-rays that can pierce through almost anything (the pictorial example showed an $\mathrm{x}$-rayed motorcycle), tire inspection systems that operate within 10 seconds, tubing inspection systems, high resolution pallet and airline igloo inspection systems, as well as pipeline and conveyer inspection systems. (Envision Product Design website, June 2005) Industry uses information from x-rays and diagnostic imaging as a means of examination for quality control and inspection.

Pipelines, the petrochemical industry, nuclear power plants and food processing commercially take advantage of industrial $x$-ray imaging technology. Pipelines are inspected by machines called crawlers, or JEEPs, that "x-ray" the outer metal surface circumference of pipe for defects such as corrosion or bad welds. Both register on the JEEP's meter and emit a particular sound when the pipe is found defective. Construction or maintenance workers correct the problem often by re-welding. Spherical crawlers, named PIGS, are routinely sent through the inside of pipelines to perform comparable electronic quality control inspection by emitting " $x$-rays" to secure information about defects that require maintenance.

The petrochemical construction and maintenance industries also employ information technology that $\mathrm{x}$-rays make possible. Imaging diagnoses construction quality with nondestructive nuclear resonance inspection (NNR) techniques. Maintenance of petrochemical industrial boilers and refiners during a unit shutdown also use quality control x-ray inspection techniques somewhat similar to NNR and that used on pipelines. Nuclear power plants x-ray the containment walls to prove quality of construction. Food examination is also a big business for x-ray technology.

In the food industry, manufacturer Cintex's bold advertisement proclaims, "We offer the widest range of food X-Ray Systems in the world. Our design team can create or adapt existing machines to suit your application and a wide choice of transport systems and reject device options are also available, offering a customised solution to your inspection requirements." Cintex cites that typical applications of its X-Ray Systems are "Fresh and Frozen Foods, Packaged Foods, Pharmaceuticals, Bakery Products, Health Foods, Confectionary Products, Chicken Fillets and Meat Products, Liquids, Soups and Sauces, Loose Powders, Granular Materials and Glass Jars.” (Cintex website, 2005) Moreover, the political food debate in 2002 found Health Canada urging Ottawa to extend the use of food irradiation - the controversial food safety technique that zaps bacteria in food with radiation. Proponents say the process can prevent health crises like mass E. coli outbreaks, but critics fear it may harm human health. Canada irradiates wheat and some seeds, but Health Canada wants to extend the technique to meat and poultry. "The question really is what took them so long," says Doug Powell of the Food Safety Network. On Monday, Health Canada will officially recommend ground beef, fish, shrimp and mangoes be eligible for the controversial process. Irradiation is like a food $\mathrm{X}$-ray, only instead of taking a picture; the food is zapped with a radioactive beam. Within seconds any bacteria or germs on the food are killed and the food is sterilized. (CTV News Staff, November 25, 2002)

It appears x-ray information systems that commercially examine and inspect our food are growing. 
In summary, this article presented an overview of Roentgen's x-rays and some information systems the discovery made possible by citing medical, scientific and commercial uses. The brief history pointed out $\mathrm{x}$-ray's hazardous risks and precautions taken. It seems the discovery continues to promote new knowledge and insight. Roentgen's scientific contributions and his belief that knowledge should be for all literally changed the world's future. In conclusion, it seems appropriate to ask a few questions before closing: Are there other types of unknown radiation or fantastic kinds of energy produced by nature still waiting to be discovered? Are there more "unknown rays," different kinds of "X-rays," or maybe "Y-rays" or "Z-rays," or perhaps "cosmic waves" in the universe yet to be harnessed? The easy scientific recommendation is to say safely do more research to find out! Further, x-rays that make possible information systems for diagnostic imaging and treatment do have some hazards associated with the procedures. An honest medical recommendation is inform people better concerning any health risks associated with radiation exposure. Finally, commercial and industrial information systems that use $\mathrm{x}$-rays will continue to expand. In historical retrospect, Wilhelm Conrad Roentgen's breakthrough discovery of x-rays probably did deserve the honor of being awarded the first Nobel Prize in Physics.

\section{REFRENCES}

1. All Science Fair Projects website, June 2005. www.all-science-fair-projects.com/project797_89.html

2. Brown, Percy, MD. American Martyrs to Science through the Roentgen Rays. Published in 1936 by Charles C. Thomas Publishing of Springfield, Illinois and Baltimore, Maryland, pages 3-265.

3. Capps, Charles J. III. Buster Brown Shoe Store Experience, Nederland, Texas, circa middle 1950s.

4. Chandra X-ray Observatory launched by Harvard University on July 23, 1999, is one of NASA's flagship observatories in X-ray astronomy, website June 2005. www.chandra.harvard.edu/

5. Cintex's website, June 2005. www.cintex.co.uk/xraysystems.html

6. CTV News Staff 25Nov02 http://foodhaccp.com/msgboard.mv?parm_func=showmsg+parm_ msgnum $=1006058$

7. Edeiken, Jack, MD. Roentgen Diagnosis of Diseases of Bone Volume One: Third Edition. Published in 1981 by Williams \& Wilkins Publishing of Baltimore and London, pages 1-827.

8. Edeiken, Jack, MD. Roentgen Diagnosis of Diseases of Bone Volume Two: Third Edition. Published in 1981 by Williams \& Wilkins of Baltimore and London, pages 829-1557.

9. Envision Product Design website, 7800 King Street, Anchorage, Alaska 99518, June 2005. ttp://cmosxray.com/?OVRAW=security\%2Bxray\&OVKEY=security\%20xray\&OVMTC

10. Fenster, Julie M. Mavericks, Miracles, and Medicine: The Pioneers Who Risked Their Lives To Bring Medicine into the Modern Age Chapter Two Wilhelm Roentgen: A Peculiar Light. Published in 2003 By Carroll \& Graf Publishers, New York, pages 19-33.

11. Friedman, Meyer, MD and Gerald W. Friedland, MD. Medicine's 10 Greatest Discoveries: Chapter 6 Wilhelm Roentgen and the X-ray Beam. Published in 1998 by the Kingsley Trust Association Publication Fund established by the Scroll and Key Society of Yale College, Yale University, pages 115-132.

12. Health Canada: The Consumer and Clinical Radiation Protection Bureau website on Medical X-rays and

13. Mammography, June 2005. www.hc-sc.gc.ca/hecs-sesc/ccrpb/xraymammo.htm

14. Merriam-Webster's 2005 Online Dictionary www.merriam-webster.com

15. Montgomery, John L. MD, guest editor, with Gary Legwold. "Diagnostic imaging: Finding new ways to see; seeing new ways to cure," Postgraduate Medicine Online. Volume 102, Number 6, December 1997, page 144. John L. Montgomery, MD, is chairman of the department of radiology and professor of medicine, Texas A\&M University Health Science Center College of Medicine, Temple Campus, and president of Scott and White Clinic, Temple, Texas. Gary Legwold is a freelance medical writer based in MN. www.postgradmed.com/issues/1997/12_97/feature.htm

16. White, Rick C. The Roentgen Lecture and Lab Visitation, in Wurzburg, Germany at the University of Wurzburg campus and park, May 2005.

17. Wikipedia 2005 Online Dictionary: www.wikipedia.com

18. Womenshealthchannel.com: www.womenshealthchannel.com 